\title{
Effect of Isosorbide Dinitrate Infusion on the Canine Left Ventricular Force-Length Relationship
}

\author{
Yasuyuki Nakamura, M.D., Kouichi Takeda, M.D., \\ Ryutaro Kadota, M.D., and Shigeru YaGI, M.D.
}

SUMMARY

Recently, the slope $\left(E_{c}\right)$ of the left ventricular $(\mathrm{LV})$ end-systolic force-diameter $\left(F_{e s}-D_{e s}\right.$ ) relationship has been proposed as a new index for assessing myocardial contractility. Using this relationship, the effects of ISDN on LV myocardial contractility were evaluated in 10 healthy adult mongrel dogs. After the intravenous infusion of propranolol and atropine to produce autonomic blockade, the inferior vena cava was gradually occluded for $20 \mathrm{sec}$ to decrease preload while the dogs were kept apneic. The LV diameter was measured by ultrasonic crystals and LV pressure was measured by a micromanometer. After the control measurements, the dogs received intravenous ISDN $(1,5,10$, or $50 \mu \mathrm{g} / \mathrm{kg} / \mathrm{min})$, and inferior vena caval occlusion was repeated. $\mathrm{E}_{\mathrm{c}}$ and the extrapolated diameter intercept $\left(\mathbf{D}_{0}\right)$ of the LV Fes-Des relationship were determined for each dog from the end-systolic data. The differences in heart rate between the control state and ISDN infusion at any dose were not statistically significant. The $E_{c}$ and $D_{0}$ values also showed no significant changes with ISDN infusion (Ec: $80 \pm 19,83 \pm 20,84 \pm 17,82 \pm 24$, and $87 \pm 24 \mathrm{~g}$ / $\mathrm{cm}$ for $0,1,5,10$, and $50 \mu \mathrm{g} / \mathrm{kg} / \mathrm{min}$, respectively. $\mathrm{D}_{0}: 1.38 \pm 0.42,1.38 \pm 0.40$, $1.38 \pm 0.38,1.34 \pm 0.40$, and $1.36 \pm 0.40 \mathrm{~cm}$ for $0,1,5,10$, and $50 \mu \mathrm{g} / \mathrm{kg} / \mathrm{min}$, respectively). These findings suggested that intravenous ISDN did not affect myocardial contractility in the normal in situ canine left ventricle. (Jpn Heart J 34: 91-101, 1993.)

\section{Key Words:}

Myocardial contractility Intact heart Cylinder model

$\mathrm{N}^{1}$

ITRATES are commonly used for the treatment of congestive heart failure and ischemic heart disease. The effects of these drugs on the failing heart, i.e., an improvement of left ventricular (LV) pump performance and a decrease in LV filling pressure, are considered to be generated primarily by a reduction in preload. ${ }^{(1)-3)}$ Although some investigators have reported that nitrates improved LV contractility in patients with ischemic heart disease, ${ }^{4), 5)}$ it is

From the Department of Medicine, Division of Hypertension and Cardiorenal Disease, Dokkyo University School of Medicine, Mibu, Tochigi, Japan.

Mailing address: Yasuyuki Nakamura, M.D., Department of Medicine, Division of Hypertension and Cardiorenal Disease, Dokkyo University School of Medicine, Mibu, Tochigi 321-02, Japan.

Received for publication May 1, 1992.

Accepted October 16, 1992. 
suspected that there was actually only an indirect effect on myocardial contractility that was mediated via the action of these drugs on the pathologic coronary arteries. Several studies have evaluated the effect of nitrates on isolated heart muscle preparations ${ }^{6-8)}$ or on the intact heart ${ }^{9-11)}$ using conventional indices of cardiac performance. However, strictly speaking, none of them have examined the effect of nitrates on myocardial contractility in the intact heart.

We have recently proposed a new model (Fig. 1) for the evaluation of myocardial contractility in the intact left ventricle, ${ }^{12)}$ and the validity of this model has been confirmed by experiments in dogs ${ }^{13)}$ and humans. ${ }^{14)}$ The purpose of this study was to confirm that isosorbide dinitrate (ISDN) has no direct positive inotropic effect on the intact normal canine heart, and to support the hypothesis that the significant effect of nitrates on congestive heart failure or ischemic heart disease is produced via their influence on the systemic, pulmonary, and coronary circulations, and not by a direct effect on the myocardium.

\section{MeTHODS}

\section{Animal preparation}

Ten healthy adult mongrel dogs $(11.0 \pm 1.0 \mathrm{~kg})$ were anesthetized with intravenous pentobarbital sodium $(26 \mathrm{mg} / \mathrm{kg})$ and instrumented as described in detail elsewhere. ${ }^{13)}$ In brief, the dogs were ventilated via an endotracheal tube using positive pressure respiration. Thoracotomy was performed through the left fourth intercostal space and the pericardium was opened. After a micromanometer-tipped catheter (MPC500, Millar Instruments) was balanced in a constanttemperature water bath $\left(37^{\circ} \mathrm{C}\right)$, it was inserted through the apex of the left ventricle and held in place by a purse-string suture. A catheter inserted into the right femoral vein served for the infusion of drugs and fluid, while another catheter was inserted into the right femoral artery for blood gas analysis. Ties were loosely placed around the inferior vena cava for use when modifying the preload. A pair of ultrasonic crystals was implanted in the LV endocardium of each dog to provide continuous measurements of the LV anterior-posterior diameter (ultrasonic dimension system model UDM-5C, MECC, Japan, Fig. 2). The stability of the conformation of the LV pressure-diameter loops was monitored with an oscilloscope during the period when the preload was being decreased.

\section{Experimental protocol}

Arterial blood gas was analyzed (model ABL4, Radiometer, Copenhagen). Arterial $\mathrm{PO}_{2}$ and $\mathrm{PCO}_{2}$ were respectively maintained at pressures greater than $100 \mathrm{mmHg}$ and less than $40 \mathrm{mmHg}$, despite any alterations in the inspired frac- 


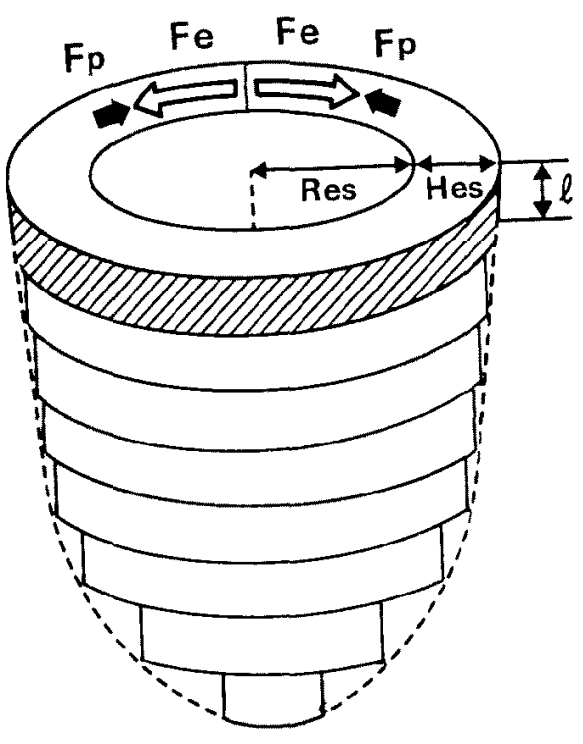

Fig. 1. Diagram of the cylinder model of the left ventricle. $\mathrm{F}_{\mathrm{r}}=$ end-systolic total circumferential force on the cylinder $(g) ; F_{p}=$ external load, end-systolic total circumferential force on the cylinder $(\mathrm{g}) ; \mathrm{H}_{\mathrm{es}}=$ end-systolic cylinder wall thickness; $1=$ cylinder height of $1 \mathrm{~cm} ; R_{e s}=$ end-systolic cylinder radius $(\mathrm{cm})$.
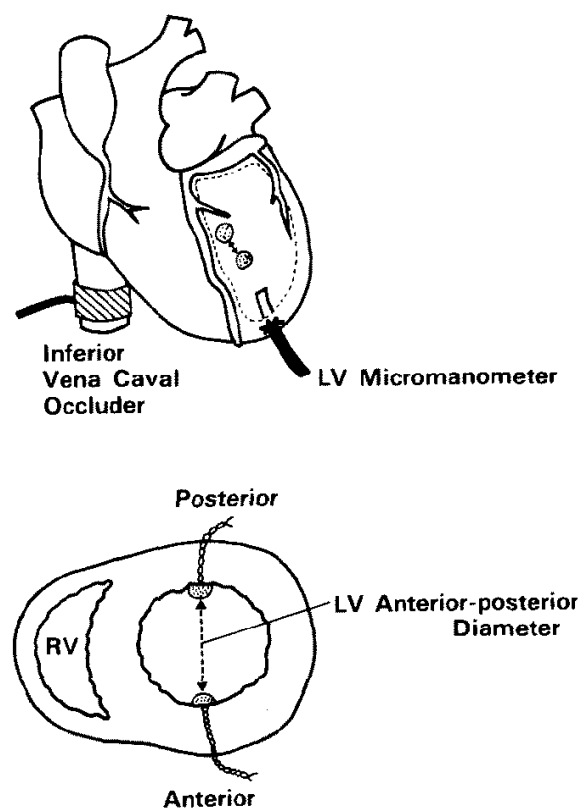

Fig. 2. The micromanometer, the location of the pair of crystals used for measuring the left ventricular diameter, and the inferior vena caval occluder used for preload reduction. LV = left ventricle; $R V=$ right ventricle.

tion of oxygen, ventilation rate, and tidal volume. Lead II of the surface electrocardiogram (ECG) was recorded. A major reflex change of autonomic tone was defined as an increase or decrease in the heart rate of greater than 10 beats $/ \mathrm{min}$ over the course of any vena caval occlusion. ${ }^{15)}$ Autonomic blockade (betaadrenergic and vagal blockade) was induced with $2 \mathrm{mg} / \mathrm{kg}$ propranolol and $0.2 \mathrm{mg} / \mathrm{kg}$ atropine i.v. ${ }^{15), 16)}$ At least $10 \mathrm{~min}$ after the initiation of autonomic blockade, the inferior vena cava was gradually occluded for $20 \mathrm{sec}$ while the dog was apneic until the systolic LV pressure reached $80 \mathrm{mmHg}$. Data were initially recorded during a steady-state period after occlusion to obtain the control occlusional LV pressure, ECG, and LV anterior-posterior diameter. The inferior vena cava was then released and the systolic pressure was allowed to return to the baseline level.

After the control measurements, the dogs intravenously received ISDN, $1 \mu \mathrm{g} / \mathrm{kg} / \mathrm{min}$ via an infusion pump (STC-523, Terumo, Japan), and at least $5 \mathrm{~min}$ were allowed to elapse before measurements were repeated. Then, inferior vena caval occlusion was performed again and the data were recorded and stored. A special ISDN infusion catheter [infusion kit for nitroglycerin (type E), 
Japan Medical Supply] was used, because ISDN is only minimally absorbed by this tube. Whenever the arterial pressure became excessively low after ISDN infusion, the dogs were given appropriate intravenous fluid supplementation (Solita T3, Shimizu Pharmaceutical Co, Japan). After completion of the initial ISDN study, doses of 5,10 , and $50 \mu \mathrm{g} / \mathrm{kg} / \mathrm{min}$ were tested in the same manner. Data were simultaneously stored in a hard disk memory at $1-\mathrm{msec}$ intervals by a computer system (PC9801VX, NEC, Japan). The final arterial blood gas analysis showed a $\mathrm{PO}_{2}>90 \mathrm{mmHg}$ and a $\mathrm{PCO}_{2}<45 \mathrm{mmHg}$. No antiarrhythmic agents were used and no arrhythmias occurred during caval occlusion. Micromanometer drift was less than $1.0 \mathrm{mmHg}$ throughout the course of the study, and positions of the ultrasonic crystals were confirmed to be appropriate by necropsy.

\section{Data analysis and theoretical background}

Instantaneous $\mathrm{LV}$ pressure $(\mathrm{P}, \mathrm{mmHg})$ and diameter $(\mathrm{D}, \mathrm{cm})$ data recorded from several cardiac cycles during the manipulation of preload were used for the construction of LV force-diameter loops. The LV circumferential force $(F)$ was calculated from the equation $\mathrm{F}=\mathrm{P} \cdot \mathrm{D} / \pi_{\mathrm{a}} .^{12), 13)}$ Loops constructed for one dog are shown in Fig. 3 as a representative example. End-systole was defined as the upper left corner of the $\mathbf{L V}$ pressure-diameter loop. ${ }^{12,, 13), 17,18)}$ In the present model, LV end-systolic circumferential force $\left(\mathrm{F}_{\mathrm{es}}=\mathrm{P}_{\mathrm{es}} \cdot \mathrm{D}_{\mathrm{es}} / \pi \mathrm{a}\right.$, where $\mathrm{P}_{\mathrm{es}}=\mathrm{LV}$

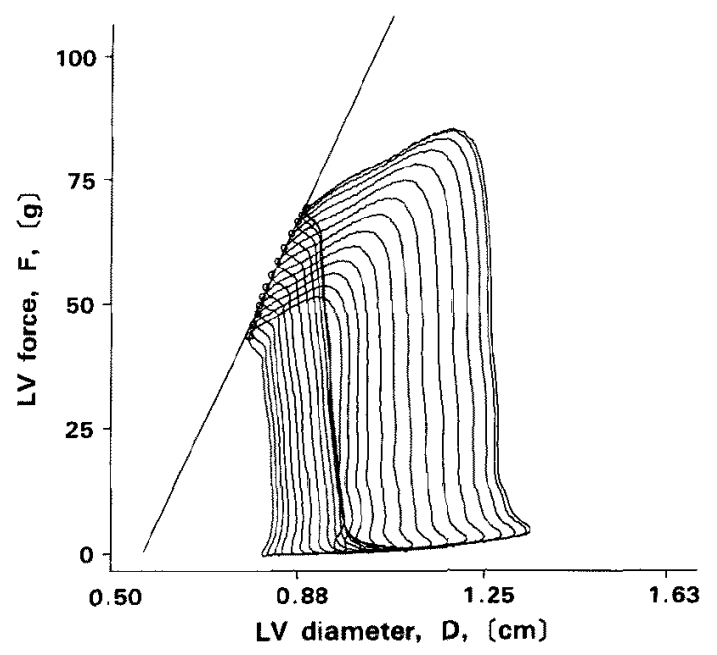

Fig. 3. Effect of isosorbide dinitrate on the left ventricular $(\mathrm{LV})$ end-systolic forcediameter $\left(F_{e s-D} D_{e s}\right)$ relation. Representative $L V$ circumfcrential forcc-diameter loops in the control contractile state obtained from one dog in response to inferior vena caval occlusion. Upper left corners of loops represent the end-systolic point in each cardiac cycle. Regression lines were estimated from the data for the $L V F_{e s}-D_{e s}$ relation. $\mathrm{D}=$ diameter $\mathrm{F}=$ force. 
end-systolic pressure, $D_{\mathrm{s}}=\mathrm{LV}$ end-systolic diameter, and a denotes the conversion factor of $0.735 \mathrm{mmHg} \cdot \mathrm{g}^{-1} \cdot \mathrm{cm}^{2}$ ) was assumed to be linearly proportional to myocardial length. Thus, LV end-systolic force $\left(F_{c s}, g\right)$ was expressed as follows:

$$
\mathrm{F}_{\mathrm{es}}=\pi \mathrm{E}_{\mathrm{c}} \cdot\left(\mathrm{D}_{\mathrm{es}}-\mathrm{D}_{\mathrm{o}}\right)
$$

where $\mathrm{E}_{\mathrm{s}}$ denotes the slope of the $\mathrm{LV}$ end-systolic force-length relation (which was used as an index of LV wall performance), and $D_{0}$ is the basal LV diameter. The linear regression equation for the $L V F_{\text {ss- }}-D_{\text {es }}$ relation was obtained as Equation 2:

$$
\mathrm{F}_{\mathrm{cs}}=\mathrm{A} \cdot\left(\mathrm{D}_{\mathrm{es}}-\mathrm{B}\right)
$$

where $\mathrm{A}$ is the regression coefficient and $\mathrm{B}$ is the $\mathrm{X}$-axis intercept. Finally, $\mathrm{E}_{\mathrm{c}}$ and $\mathrm{D}_{0}$ were derived in the following manner from Eqs. 1 and 2, respectively:

$$
\begin{gathered}
\mathrm{E}_{\mathrm{c}}=\mathrm{A} / \pi \\
\mathrm{D}_{0}=\mathrm{B}
\end{gathered}
$$

Digital data recorded on the hard disk were processed using a computer system (PC9801VX, NEC) and software developed in our laboratory. This system allowed us to obtain force-diameter loops, determine the end-systolic point in each cardiac cycle, estimate the regression equation for the $L V F_{e s-D e s}$ relation (as well as the values of $E_{c}$ and $D_{0}$ ), and draw entire curves for the $L V F_{e s-} D_{e s}$ formula.

\section{Statistical analysis}

Data are expressed as the mean \pm SD. The statistical significance of differences between means was assessed by Student's paired t-test. Linear regression by the least squares method was used to fit data to the LV Fess $-D_{e s}$ relation.

\section{Resurts}

Table I shows the heart rate, LV end-systolic pressure $\left(\mathrm{P}_{\mathrm{es}}\right)$, diameter $\left(\mathrm{D}_{\mathrm{ss}}\right)$, force $\left(F_{e s}\right), E_{c}$, and $D_{0}$ data in the control study and after ISDN infusion. The difference in heart rate between the control study and ISDN infusion at any dose was not statistically significant, and was less than 5 beats $/ \mathrm{min}$ in all dogs. Thus, major reflex changes of the autonomic tone acting on the heart were not noted. LV Pes decreased from $126 \pm 21$ to $91 \pm 12 \mathrm{mmHg}$ during the control IVC occlusion. Similarly it decreased from $125 \pm 18$ to $90 \pm 7 \mathrm{mmHg}$ during the infusion of ISDN at $1 \mu \mathrm{g} / \mathrm{kg} / \mathrm{min}(\mathrm{p}<0.01)$, from $120 \pm 17$ to $89 \pm 7 \mathrm{mmHg}$ at $5 \mu \mathrm{g} / \mathrm{kg} / \mathrm{min}$ $(\mathrm{p}<0.01)$, from $118 \pm 17$ to $89 \pm 10 \mathrm{mmHg}$ at $10 \mu \mathrm{g} / \mathrm{kg} / \mathrm{min}(\mathrm{p}<0.01)$, and from 
Table I. Effect of Isosorbide Dinitrate Infusion on Myocardial Contractility

\begin{tabular}{|c|c|c|c|c|c|}
\hline & \multirow{2}{*}{ Control } & \multicolumn{4}{|c|}{ Infusion rate $(\mu \mathrm{g} / \mathrm{kg} / \mathrm{min})$} \\
\hline & & 1 & 5 & 10 & 50 \\
\hline HR (bpm) & $113 \pm 15$ & $115 \pm 15$ & $114 \pm 16$ & $114 \pm 16$ & $114 \pm 16$ \\
\hline $\mathrm{Pes}_{\mathrm{es}}(\mathrm{mmg})$ & $126 \pm 21$ & $125 \pm 18$ & $120 \pm 17 *$ & $118 \pm 17$ & $111 \pm 14 * *$ \\
\hline $\mathrm{D}_{\mathrm{ss}}(\mathrm{cm})$ & $2.12 \pm 0.56$ & $2.07 \pm 0.51$ & $2.01 \pm 0.55^{* *}$ & $1.98 \pm 0.52^{* *}$ & $1.93 \pm 0.52^{* * *}$ \\
\hline$F_{\text {es }}(g)$ & $183 \pm 58$ & $175 \pm 48$ & $166 \pm 54^{* *}$ & $161 \pm 50^{*}$ & $147 \pm 45^{* *}$ \\
\hline $\mathrm{E}_{\mathrm{c}}(\mathrm{g} / \mathrm{cm})$ & $80 \pm 19$ & $83 \pm 20$ & $84 \pm 17$ & $82 \pm 24$ & $87 \pm 24$ \\
\hline$D_{0}(\mathrm{~cm})$ & $1.38 \pm 0.42$ & $1.38 \pm 0.40$ & $1.38 \pm 0.38$ & $1.34 \pm 0.40$ & $1.36 \pm 0.40$ \\
\hline
\end{tabular}

$* \mathrm{p}<0.05, * \mathrm{p}<0.01$ (control vs. isosorbide dinitrate).

$D_{e s}=$ left ventricular end-systolic diameter; $D_{0}=$ extrapolated diameter intercept of the left ventricular $F_{e s}$. Des relation; $E_{c}=$ slope of the left ventricular $F_{e s}-D_{e s}$ relation; $F_{e s}=$ left ventricular end-systolic force; $H R=$ heart rate; $P_{c s}=$ left ventricular end-systolic pressure.

$111 \pm 14$ to $83 \pm 7 \mathrm{mmHg}$ at $50 \mu \mathrm{g} / \mathrm{kg} / \mathrm{min}(\mathrm{p}<0.01)$. The $P_{\text {es }}$ value before IVC occlusion was significantly lower in the 5 and $50 \mu \mathrm{g} / \mathrm{kg} / \mathrm{min}$ ISDN studies when compared with the control study. Des and $F_{e s}$ were also significantly decreased in the 5,10 and $50 \mu \mathrm{g} / \mathrm{kg} / \mathrm{min}$ ISDN studies.

In all cases, the $L V F_{e s-} D_{e s}$ relation showed near linearity (Fig. 4). Ec did not change at any level of ISDN infusion in comparison with the control level [80 \pm 19 vs. $83 \pm 20(1 \mu \mathrm{g} / \mathrm{kg} / \mathrm{min}), 84 \pm 17(5 \mu \mathrm{g} / \mathrm{kg} / \mathrm{min}), 82 \pm 24(10 \mu \mathrm{g} / \mathrm{kg} / \mathrm{min})$, and $87 \pm 24 \mathrm{~g} / \mathrm{cm}(50 \mu \mathrm{g} / \mathrm{kg} / \mathrm{min})]$. Do also did not change with any of the ISDN doses infused $[1.38 \pm 0.42$ vs. $1.38 \pm 0.40(1 \mu \mathrm{g} / \mathrm{kg} / \mathrm{min}), 1.38 \pm 0.38(5 \mu \mathrm{g} / \mathrm{kg} /$ $\mathrm{min}), 1.34 \pm 0.40(10 \mu \mathrm{g} / \mathrm{kg} / \mathrm{min})$, and $1.36 \pm 0.40 \mathrm{~g} / \mathrm{cm}(50 \mu \mathrm{g} / \mathrm{kg} / \mathrm{min})]$. Therefore, ISDN infusion did not affect the myocardial contractile state of the canine LV myocardium.

\section{Discussion}

Although several contractility indices for evaluating myocardial performance, such as the ejection fraction (EF), the mean circumferential fiber shortening velocity $(\mathrm{mVcf})$, and $\mathrm{dP} / \mathrm{dt}_{\max }$, have been used clinically, none of these indices can accurately evaluate LV myocardial function because of the influence of preload and/or afterload. $E_{\max }$ (the slope of the LV end-systolic pressure-volume relation) appears to be an index that is independent of preload and afterload. ${ }^{17,18)}$ However, there is still the problem that this index depends on LV size (the endsystolic $L V$ volume at zero pressure, $V_{\mathrm{d}}$ ). ${ }^{19-24)}$ We have proposed a new cylinder model for the evaluation of LV myocardial contractility, ${ }^{12)}$ and recent studies 

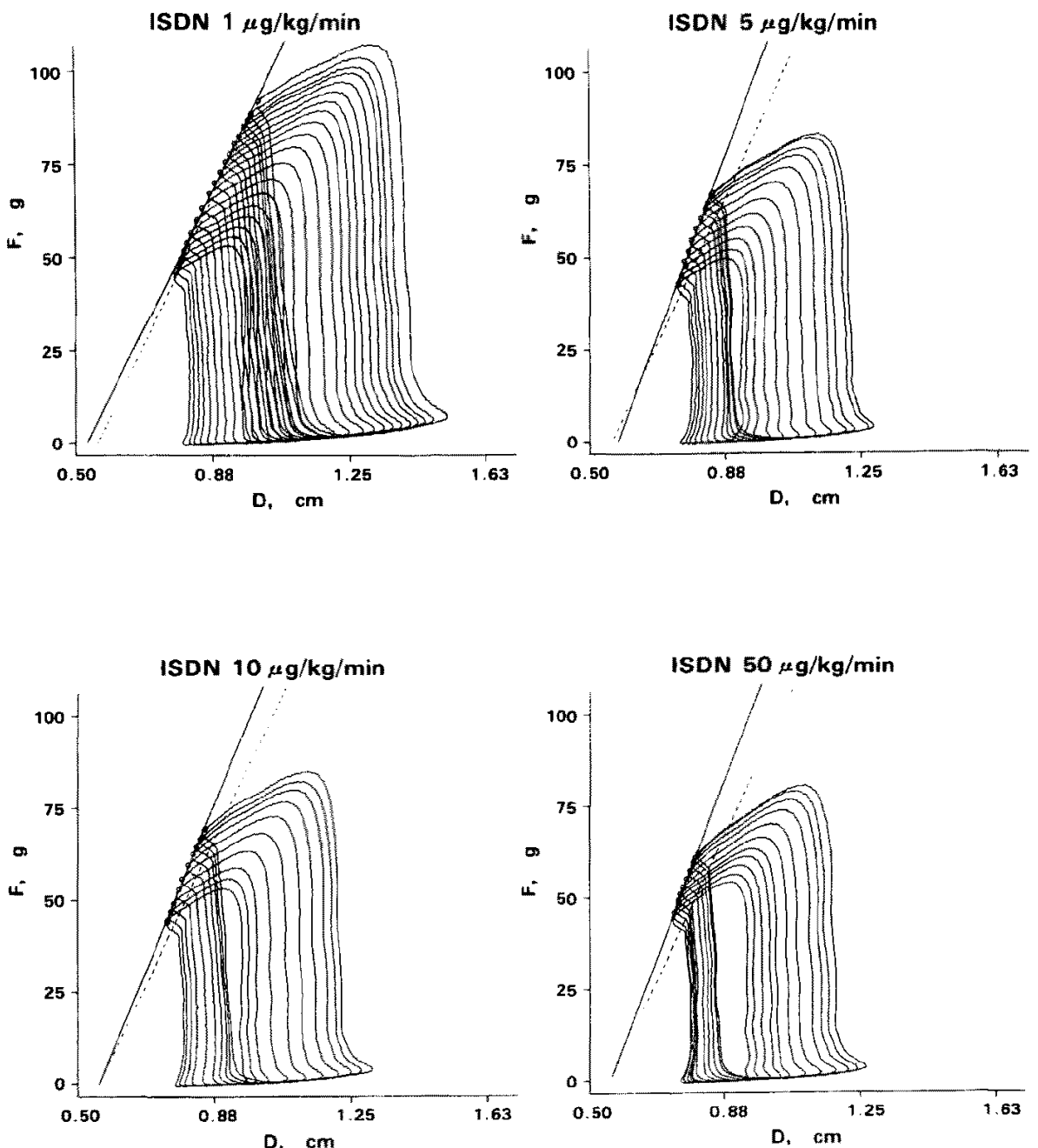

Fig. 4. Representative LV circumferential force-diameter loops after the intravenous infusion of isosorbide dintrate (ISDN). Broken lines indicate the LV Fes-Des relation during the control contractility state. Solid lines are for the data obtained after the infusion of $\operatorname{ISDN}(1,5,10$ or $50 \mu \mathrm{g} / \mathrm{kg} / \mathrm{min})$.

have indicated that $E_{c}$ is a reliable index for assessing the contractility of the intact canine and human left ventricle. ${ }^{13), 14)}$ In the present study, we accordingly evaluated the effect of ISDN infusion on the LV myocardium using the $E_{c}$ value.

\section{Direct effect of nitrates on myocardial contractility}

Nitrates are well known to have a strong vasodilatory effect and to decrease both preload and afterload, but investigators still disagree concerning the posi- 
tive inotropic effect of these agents. Strauer ${ }^{25)}$ reported a positive inotropic action of nitroglycerol in isolated human LV papillary muscles obtained during surgery to implant prosthetic mitral valves. Because $V_{\max }$ was significantly increased after nitroglycerol administration, he concluded that this agent directly increased the contractility of human myocardium. On the other hand, some investigators postulate that the acceleration of myocardial contractility after nitroglycerol administration is caused by a sympathetic reflex rather than a direct drug effect. Darby et $\mathrm{al}^{9,10)}$ suggested that the effect of nitroglycerin on myocardial contractility was due to increased sympathetic tone as a reflex response to hypotension, because myocardial contractility was increased in dogs after the intravenous infusion of nitroglycerin and this response was abolished by vagosympathectomy. Using beta-blocking agents, Wiener et al $^{4)}$ have also obtained similar results. Levy ${ }^{6 /}$ examined this phenomenon by studying force-frequency relationships in the isolated rabbit left atrium, and he concluded that ISDN did not alter the basic contractility mechanism. In our present study, the index $\mathrm{E}_{\mathrm{c}}$ did not change after ISDN infusion. Accordingly, we also suggest that ISDN does not directly affect the LV myocardium.

\section{Indirect effects of nitrates on myocardial contractility}

An experimental study which examined the effects of intravenous nitroglycerin infusion on regional myocardial blood flow showed that coronary flow increased immediately after intravenous nitroglycerin infusion, but then finally decreased with a rapid reduction of aortic pressure. ${ }^{(1)}$ Vatner et al ${ }^{(0)}$ studied the effects of intravenous nitroglycerin infusion on coronary blood flow and resistance, $\mathrm{LV}$ pressure and diameter, $\mathrm{dP} / \mathrm{dt},(\mathrm{dP} / \mathrm{dt}) / \mathrm{P}$, and the velocity of myocardial fiber shortening in conscious dogs. They concluded that intravenous nitroglycerin produced two phases of coronary dilatation, which led to an increase in coronary blood flow. The first phase was a direct effect of nitroglycerin on the coronary vessels, while the later phase was secondary coronary vasodilatation caused by reflex sympathetic activity. This coronary vasodilatation did not affect myocardial contractility. Nitroglycerin was infused as a bolus $(40 \mu \mathrm{g} / \mathrm{kg})$ in their experiments, whereas we used a steady infusion at $1-50 \mu \mathrm{g} / \mathrm{kg} / \mathrm{min}$, but both experiments were performed under autonomic blockade. Although we did not measure or regulate coronary blood flow, the experimental results of Vatner et $\mathrm{al}^{10)}$ and our findings suggest that the coronary vasodilatation and the changes of coronary blood flow distribution that are associated with the decrease in preload induced by nitrates had almost no indirect effect on myocardial contractility in normal hearts. Moreover, it also appears that nitroglycerin does not directly affect myocardial contractility.

On the other hand, there are many reports that nitrates promote myocar- 
dial performance in ischemic heart disease. ${ }^{4,5)}$ Strauer examined the hemodynamic effect after intravenous nitroglycerin infusion and he suggested significant increases in peak $\mathrm{dP} / \mathrm{dt}$, the cardiac index, and the stroke volume index. ${ }^{5)}$ Coronary blood flow and myocardial oxygen consumption were increased in association with the enhancement of ventricular performance. However, there are also some reports that nitrates can decreasc myocardial contractility. ${ }^{7,8)}$ It has been observed that nitrates affect subendocardial and subepicardial myocardial blood flow ${ }^{26)}$ and dilate the coronary collaterals. ${ }^{27-30)}$ These effects may provoke the abnormal distribution of coronary and myocardial blood flow and even cause the coronary steal phenomenon, ${ }^{26,31,31,32)}$ Using the LV end-systolic force-length relation, we previously detected a patient with ischemic cardiomyopathy who showed deterioration of myocardial contractility following nitroglycerin infusion. ${ }^{33)}$ This deterioration was strongly suggested to be caused by the coronary steal phenomenon, which arose due to the pharmacological effects of nitrate on the coronary vessels.

\section{Concuusion}

The effects of ISDN infusion on myocardial contractility in the intact left ventricle were evaluated using the $\mathrm{LV}$ end-systolic force-length relation in anesthetized open-chest dogs under autonomic blockade. The slope of the LV endsystolic force-length relation $\left(\mathrm{E}_{\mathrm{c}}\right.$, an index of myocardial contractility) and its diameter intercept $\left(\mathrm{D}_{0}\right)$ did not change after the intravenous infusion of ISDN $(1$, 5,10 , or $50 \mu \mathrm{g} / \mathrm{kg} / \mathrm{min}$ ). This suggests that ISDN infusion does not affect myocardial contractility in the normal in situ canine left ventricle.

\section{ACKNOWLeDGMent}

The authors are grateful to Mr. H. Shimokawa for his expert technical assistance in the preparation of the present experiments.

\section{REFERENCES}

1. Gray R, Chatterjee K, Vyden JK, Ganz W, Forrester JS, Swan HJC: Hemodynamics and metabolic effects of isosorbide dinitrate in chronic congestivc hcart failure. Am Heart J 90: 346, 1975

2. Flaherty JT, Reid PR, Kelly DT, Taylor DR, Weisfeldt ML, Pitt B: Intravenous nitroglycerin in acute myocardial infarction. Circulation 51: 132, 1975

3. Mantle JA, Russell RO, Moraski RE, Rackley CE: Isosorbide dinitrate for the relief of severe heart failure after myocardial infarction. Am J Cardiol 37: 263, 1976

4. Wiener L, Dwyer EM, Cox JW: Hemodynamic effects of nitroglycerin, propranolol, and their combination in coronary heart disease. Circulation 39: 623, 1969

5. Straucr BE, Schcrpe A: Ventricular function and coronary hemodynamics after intravenous nitroglycerin in coronary artery disease. Am Heart J 95: 210, 1978 
6. Levy JV: Effect of isosorbide dinitrate and its metabolites on rabbit atrial myocardial force-frequency relationships in vitro. Arch Int Physiol Biochim 90: 361, 1982

7. Noack E: Vergleichende Untersuchung zur pharmakodynamischen Wirkung organischer Nitrate am isolicrt perfundierten Langendorff-Herzen, in Mononitrat, ed by Kaltenbach M, Bussmann WD, Schrey A, Universitätsdruckerei und Verlag, C Wolf und Sohn, München, p 38, 1981

8. Baráth $\mathrm{H}$, Kékes $\mathrm{E}$, Strausz I: Acute global ischaemia and nitroglycerin-induced changes of the contraction-relaxation and diastolic properties of isolated rabbit heart. Acta Physiol Pol 32: 637, 1981

9. Darby TD, Sprouse JH, Walton RP: Evaluation of sympathetic reflex effects on the inotropic action of nitroglycerin, quinidine, papaverine, aminophylline, and isoproterenol. J Pharmacol Exper Therap 122: 386, 1958

10. Vatner SF, Higgins CB, Millard RW, Franklin D: Direct and reflex effects of nitroglycerin on coronary and left ventricular dynamics in conscious dogs. J Clin Invest 51: 2872, 1972

11. Narita $\mathrm{H}$ : An experimental study on effects of intravenous nitroglycerin on regional myocardial blood flow and regional myocardial contraction (in Japanese with English abstr). Hirosaki Med J 37: 274, 1985

12. Takeda K, Shimizu T, Yamamoto H, Yagi S: Human left ventricular end-systolic pressure-volume relationship in a cylinder model. Jpn Heart J 29:689, 1988

13. Takeda K, Takeda M, Shimizu T, Yagi S: Approximation of various canine left ventricular end-systolic relations by a cylinder model. Am J Physiol 258: H1300, 1990

14. Takeda K, Tamano K, Okamura A, Kobayashi N, Shimizu T, Kadota R, Yamamoto H, Yagi $\mathrm{S}$ : Slope of human left ventricular end-systolic force-length relation is independent of myocardial length. Am J Physiol 261: H1060, 1991

15. Little WC, Freeman GL, O'Rourke RA: Simultaneous determination of left ventricular end-systolic pressure-volume and pressure-dimension relationships in closed-chest dogs. Circulation 71: 1301, 1985

16. Vatner SF, Higgins CB, Franklin D, Braunwald E: Extent of carotid sinus regulation of the myocardial contractile state in conscious dogs. J Clin Invest 51: 995, 1972

17. Suga $\mathrm{H}$, Sagawa $\mathrm{K}$ : Instantaneous pressure-volume relationships and their ratio in the excised, supported canine left ventricle. Circ Res 35: 117, 1974

18. Suga H, Sagawa K, Shoukas AA: Load independence of the instantaneous pressure-volume ratio of the canine left ventricle and effects of epinephrine and heart rate on the ratio. Circ Res 32: 314, 1973

19. Alpert BS, Benton L, Olley PM: Peak left ventricular pressure/volume $\left(\mathbf{E}_{\max }\right)$ during exercise in control subjects and children with left-sided cardiac disease. Cathet Cardiovasc Diagn 7: 145, 1981

20. Suga $\mathrm{H}$, Hisano $\mathrm{R}$, Goto $\mathrm{Y}$, Yamada $\mathrm{O}$ : Normalization of end-systolic pressure-volume relation and Emax of different sized hearts. Jpn Girc J 48: 136, 1984

21. Grossman W, Braunwald E, Mann T, McLaurin LP, Green LH: Contractile state of the left ventricle in man as evaluated from end-systolic pressure-volume relations. Circulation 56: 845, 1977

22. Mehmel HC, Stockins B, Ruffmann K, Olshausen K, Schuler G, Kübler W: The linearity of the endsystolic pressure-volume relationship in man and its sensitivity for assessment of left ventricular function. Circulation 63: 1216, 1981

23. Pouleur H, Rousseau MF, Van Eyll C, VanMechelen H, Brasseur LA, Charlier AA: Assessment of left ventricular contractility from late systolic stress-volume relations. Circulation 65: 1204, 1982

24. Winnem $\mathrm{M}$, Piene $\mathrm{H}$ : Left ventricular end-systolic pressure volume relations in healthy young men. Eur Heart J 7: 961, 1986

25. Strauer BE: Evidence for a positive inotropic effect of nitroglycerol and the isolated human ventricular myocardium. Pharmacol Res Commun 3: 377, 1971

26. Armstrong PW, Walker DC, Burton JR, Parker JO: Vasodilator therapy in acute myocardial infarction: A comparison of sodium nitroprusside and nitroglycerin. Circulation 52: 11 18, 1975

27. Cohen MV, Downey JM, Sonnenblick EH, Kirk ES: The effects of nitroglycerin on coronary collaterals and myocardial contractility. J Clin Invest 52: 2836, 1973

28. Capurro N, Kent KM, Epstein SE: Effects of intracoronary and intravenous nitroglycerin on coronary collateral function. J Pharmacol Exp Ther 199: 262, 1976

29. Abrams J: Hemodynamic effects of nitroglycerin and long acting nitrates. Am Heart J 110: 216, 1985

30. Brown BG: Responses of normal and diseased epicardial coronary arteries to vasoactive drugs: quantitative arteriographic studies. Am J Cardiol 56: 23E, 1985 
31. Cohen MV, Kirk ES: Differential response of large and small coronary arteries to nitroglycerin and angiotensin: Autoregulation and tachyphylaxis. Circ Res 33: 445, 1973

32. Flaherty JT: Comparison of intravenous nitroglycerin and sodium nitroprusside in acute myocardial infarction. Am J Med 74(6B): 53, 1983

33. Takeda K, Okamura A, Tamano K, Kobayashi N, Kadota R, Nakamura Y, Nagashima K, Nishiyama $\mathrm{Y}$, Yamamoto $\mathrm{H}$, Yagi S: Deterioration of myocardial contractility induced by nitroglycerin infusion in a case of ischemic cardiomyopathy (in Japanese with English abstr). J Cardiol 20: 1037, 1990 